\title{
JURISPRUDENCIA AMBIENTAL EN LAS ISLAS BALEARES (SEGUNDO SEMESTRE 2018)
}

\author{
Josep Manuel Gómez GonzÁlez \\ Departamento de Territorio e Infraestructuras \\ Consejo Insular de Mallorca \\ jmgomez@conselldemallorca.net
}


Sumario: 1. Introducción. 2. Los defectos de tramitación de disposiciones territoriales y la vía de las impugnaciones indirectas: la sentencia del Tribunal Superior de Justicia de las Islas Baleares número 752/2018, de 17 de julio (ID. Cendoj 07040330012018100427). 3. Sobre la responsabilidad patrimonial derivada de la protección ambiental de costas. La sentencia del Tribunal Superior de Justicia de las Islas Baleares número 764/2018, de 3 de septiembre (Id. Cendoj 07040330012018100434).

\section{INTRODUCCIÓN}

La jurisprudencia ambiental de este semestre vuelve a destacar por la ausencia de casos destacables en materia ambiental y territorial. Así, esta revisión se centra en dos asuntos eminentemente procedimentales que son relevantes, precisamente, con relación a posibles defectos de tramitación de sendas disposiciones normativas.

Por una parte tenemos una sentencia con relación a la impugnación de una batería de instrumentos de ordenación territorial y urbanísticas donde la demandante intenta aplicar la doctrina desarrollada con relación a la conexión de actos administrativos especialmente vinculados entre sí y con la finalidad de conseguir una cadena de impugnaciones indirectas con el consiguiente efecto de anulación de disposiciones derivadas jerárquicamente. Ello lo hacemos con el análisis de la sentencia del Tribunal Superior de Justicia de las Islas Baleares número 752/2018, de 17 de julio. También analizaremos un caso de responsabilidad patrimonial derivada de la protección ambiental de costas con relación a la fiabilidad de la información proporcionada por un ayuntamiento sobre una materia que alcanza la delimitación del dominio público estatal de costas. Ello, será con la sentencia del Tribunal Superior de Justicia de las Islas Baleares número 764/2018, de 3 de septiembre.

\section{LOS DEFECTOS DE TRAMITACIÓN DE DISPOSICIONES} TERRITORIALES Y LA VÍA DE LAS IMPUGNACIONES INDIRECTAS, LA SENTENCIA DEL TRIBUNAL SUPERIOR DE JUSTICIA DE LAS ISLAS BALEARES NÚMERO 752/2018, DE 17 DE JULIO (ID. CENDOJ 070403300120118100427)

El objeto del pleito es la impugnación, por una parte, del acuerdo del Pleno del Consejo Insular de Menorca, adoptado en sesión celebrada el 21 de septiembre de 2015, por el cual se aprobó definitivamente la modificación puntual del Sector C del Plan Parcial de Sant Tomás des Migjorn Gran 
(Menorca); y por otra parte, la impugnación de la sentencia de la Sala no. 1121, de 20/12/2010, más concretamente la impugnación indirecta de la señalada sentencia para entender que es nula de pleno derecho. Con esta maniobra se pretende conseguir que la resolución de la Sala, arrastre la nulidad en cadena de todos los actos vinculados, al dejarlos sin sostén jurídico. Por lo tanto, se persiguen por la vía indirecta todos aquellos acuerdos del Consejo Insular de Menorca vinculados con la sentencia, de manera que se genere una reacción de invalidez en cadena. En detalle, la demanda, según recopilación la sentencia solicitaba:

"SEGUNDO.- La demanda se formalizó en plazo legal. Se solicitó entonces el recibimiento del juicio a prueba "[...] sobre cualquier punto que sea negado de adverso y sobre cualquier informe que haya sido emitido en el pleito, aportado o alegado por la Administración demandada, y, en especial se señalan como prueba, los documentos que acompañan al presente escrito que, de no ser aceptadas como tales las copias aportadas, se provea lo pertinente". Y se solicitaba también, además de la estimación del recurso y la imposición de las costas del juicio, que la sentencia de la Sala declare:

"[...] no ser conforme a derecho las siguientes resoluciones impugnadas:

10- Directamente, la "MODIFICACIÓN PUNTUAL DEL SECTOR C DEL PLAN PARCIAL DE SANT TOMÁS DE ES MIGJORN GRAN" (Exp. NUMO00)."

$2^{\circ}$ Indirectamente, la de "APROBACIÓN DEFINITIVA DEL PLAN 'TERRITORIAL INSULAR DE MENORCA", adoptado en la sesión extraordinaria de fecha 25 de abril de 2003 (publicado en el BOIB núm. 69 EXT, de 16 de mayo de 2003), de conformidad con lo dispuesto el artículo 27.2 de la $U$.

$3^{\circ}$ Indirectamente, la de "LEVANTAMIENTO DE LA SUSPENSIÓN ACORDADA RESPECTO AL INICIO DE LA EFICACIA DE LAS DETERMINACIONES DEL PLAN TERRITORIAL INSULAR DE MENORCA, RELATIVAS AL LITORAL" adoptado el 27 de octubre de 2003 (publicado en el BOIB $n^{\circ} 155$, de 8 de noviembre de 2003, de conformidad con lo dispuesto el artículo 27.2 de la LJ, si procede, en el supuesto de ser admitida la impugnación indirecta aquí instada contra Aprobación Definitiva del Plan Territorial Insular de Menorca, en la que fundamentaba su soporte jurídico. 
$4^{\circ}$ Indirectamente, la de "RECTIFICACIÓN DE ERRORES DEL PLAN TERRITORIAL INSULAR DE MENORCA", adoptado en la sesión ordinaria de 27 de octubre de 2003 (publicado en el BOIB $n^{\circ} 158$ EXT, de 14 de noviembre de 2003), de conformidad con lo dispuesto el artículo 27.2 de la LJ, si procede, en el supuesto de ser admitida la impugnación indirecta aquí instada contra Aprobación Definitiva del Plan Territorial Insular de Menorca, en la que fundamentaba su soporte jurídico.

$5^{\circ}$ Indirectamente, la de "APROBACIÓN DEFINITIVA DE LA MODIFICACIÓN DEL PLAN TERRITORIAL INSULAR DE MENORCA", adoptado en la sesión ordinaria de 26 de junio de 2006 (publicado en el BOIB $n^{\circ} 155$, de 27 de julio de 2006, de conformidad con lo dispuesto el artículo 27.2 de la LJ, si procede, en el supuesto de ser admitida la impugnación indirecta aquí instada contra Aprobación Definitiva del Plan Territorial Insular de Menorca, en la que fundamentaba su soporte jurídico"».

La defensa de la administración insular destaca el hecho de que el recurso tiene por objeto actos no susceptibles de impugnación, recae sobre cosa juzgada y se ha presentado el escrito inicial fuera del plazo establecido. Para sostener eso invoca el artículo 28 de la Ley Jurisdiccional en cuanto al acto confirmatorio y a la admisibilidad del recurso. Concretamente las peticiones son:

«Las Sentencias de 11 de septiembre de 1991, 30 de marzo de 1992, 2 de marzo y 25 de octubre de 1993, 22 de enero, 7 de julio y 22 de enero y 25 de octubre de 1994 y 7 de marzo de 1995 del Tribunal Supremo, sobre desviación procesal".

Por lo tanto, el Consell Insular de Menorca solicitaba en su contestación a la demanda que en la sentencia de la Sala:

«1.- Se declare la inadmisibilidad del recurso respecto a la aprobación definitiva el PTIMe, al levantamiento de la suspensión acordada respecto al inicio de la eficacia de las determinaciones del PTIMe, relativas al litoral, la rectificación de errores del PTIMe y la aprobación definitiva de la modificación del PTIMe.

2.-Acuerde la desestimación del recurso contencioso-administrativo respecto al acuerdo de 21 de septiembre de 2011, adoptado por el Pleno del Consell Insular de Menorca por el que se resolvió aprobar 
definitivamente la modificación puntual del Plan Parcial del Sector C de Sant Tomás de Es Migjorn Gran, confirmando en todas sus partes el acto objeto de recurso. »

Debemos destacar que en el escrito de interposición del recurso contencioso administrativo, el demandante se dirigía únicamente contra el acuerdo del Pleno del Consejo Insular de Menorca por el que se aprobó definitivamente la modificación puntual del Sector $\mathrm{C}$ del Plan Parcial de Sant Tomás des Migjorn Gran. El resto de impugnaciones indirectas provienen de un giro argumental planteado ya en sede de formalización de la demanda.

Igualmente, la parte actora denuncia la omisión de tres trámites esenciales en el procedimiento de elaboración de la disposición general, erigiendo esta falta como a causa de nulidad de pleno derecho, pero lo plantea como si el acuerdo impugnado fuera un acto administrativo y no una disposición normativa. Por ello, el Tribunal tiene que manifestar que las irregularidades procedimentales denunciadas no se pueden considerar como infracciones de los preceptos de la Ley 30/1992, de 26 de noviembre, ya que la misma se refiere al procedimiento de aprobación de actos administrativos, mientras que en el asunto analizado, nos encontramos ante un reglamento o disposición general.

Por todo ello, ya se avanza que la ausencia de los informes preceptivos y, si procede, vinculantes, a emitir por los órganos de la Administración Estatal, se trataría de una vulneración del principio de jerarquía normativa, por el hecho de que el Consejo Insular de Menorca no hubiera dado cumplimiento a ciertas determinaciones contenidas en diferentes leyes sectoriales. En concreto, la Ley 22/1988, de 28 de julio, de Costas, la Ley 11/1998, de 24 de abril, General de Telecomunicaciones y Ley 6/1998, de 13 de abril, de Régimen del Suelo y Valoraciones (vigentes entonces).

Sin embargo, constan en el procedimiento las peticiones de los informes sectoriales señalados, como el oficio remitido por la Consejera-Delegada de Ordenación del Territorio, Urbanismo y Medio Ambiente dirigido a la Dirección General de Costas, el 18 de noviembre de 2002, en el cual se interesa la emisión del informe exigido en el artículo 117.1 de la Ley de Costas. Por otra 
parte la petición fue cursada en la misma fecha tanto en el Ministerio de Medio Ambiente como la Delegación del Gobierno del Estado en las Islas Baleares.

Sobre esta cuestión formal debe destacarse el hecho de que el 18 de febrero de 2003, la Unidad de Soporte-Planeamiento Urbanístico perteneciente a la Dirección General de Costas confeccionó el informe -preceptivo y vinculanteestablecido en los artículos 112 y 117.1 de la Ley de Costas, consignando una serie de observaciones a tener en cuenta en la aprobación definitiva.

También, el 27 de febrero de 2003 se recibió un informe redactado por el Delegado del Gobierno sobre las cuestiones que se refieren a materias de competencia estatal, conteniendo una serie de observaciones sobre energía, declaraciones de interés general en agricultura y medio ambiente, aguas marinas, costas, zona portuaria y aeroportuaria, y, en el punto 9, se recogió que «Tendrá que contemplar la normativa específica de las zonas declaradas de interés para la defensa nacional y delimitar sobre plano los terrenos, edificaciones e instalaciones, incluidas, sus zonas de protección, afectos a la Defensa Nacional.»

Ante esta respuesta, el 19 de marzo de 2003, la Presidenta del Consejo Insular comunicó al Delegado del Gobierno que las observaciones no eran sustanciales y que se habían recogido en el texto definitivo, interesando a la celebración de una reunión, la cual tuvo lugar el 26 de marzo siguiente.

Finalmente, el 25 de abril de 2003, el Pleno del Consejo Insular aprobó el Plan Territorial de la Isla de Menorca, en la cual se consignó una norma temporal y condicional relativa a la suspensión de la eficacia de las prescripciones referentes al litoral, hasta que se recibiera el informe favorable establecido en el artículo 117.2 de la Ley de Costas. Recibido el informe positivo, el Pleno levantó la suspensión de la vigencia de tales artículos el 27 de octubre de 2003 (BOIB n‥ 155, de 8 de noviembre).

Por todo ello, la impugnación indirecta del Plan Territorial Insular de Menorca, decae. $Y$ es que, faltando respuesta del demandante a la pretensión de inadmisión del recurso que figura en las dos contestaciones a la demanda, el Tribunal considera que, independientemente que la impugnación indirecta de la sentencia de la Sala no. 1121/2010 no se incluyera en el escrito de 
interposición del recurso sino que se haya añadido después, concretamente en la demanda, en definitiva, esta impugnación recae sobre cosa juzgada. Así se considera que se incurre en la causa de inadmisión recogida en el artículo 69. d) de la Ley 29/1998.

Igual fortuna obtiene la impugnación de acuerdo del Pleno del Consejo Insular de Menorca, adoptado en sesión de 21 de septiembre de 2015, por el cual se aprobó definitivamente la modificación puntual del Sector $\mathrm{C}$ del Plan Parcial de Sant Tomás des Migjorn Gran. Aquí, el demandante insiste en que en la elaboración del Plan Territorial Insular de Menorca faltó el informe preceptivo del art. 117.2 de la Ley de Costas; pero el Tribunal mantiene sobre este tema: por un lado, que ya consta que con ocasión de la adaptación del Plan Parcial a las Normas Subsidiarias se solicitó el informe de Costas; por otro lado, que también consta que este informe fue emitido en sentido favorable, justamente porque el Sector $\mathrm{C}$, que era el más alejado del litoral, en definitiva, no contaba con ningún tipo de afectación de la Ley de Costas. Por todo eso, el acuerdo de aprobar definitivamente la modificación puntual del Plan Parcial del Sector $\mathrm{C}$ de Sant Tomás des Migjorn Gran, a pesar de lo aducido en la demanda, es conforme a Derecho.

Pero es que además, el Tribunal recuerda a la demandante que la modificación puntual del Plan Parcial de Sant Tomás des Migjorn Gran no se ha dictado en aplicación del Plan Territorial Insular de Menorca sino que se dicta en aplicación de las Normas Subsidiarias des Migjorn Gran. En efecto, adaptadas las Normas Subsidiarias des Migjorn Gran al Plan Territorial Insular de Menorca, posteriormente el Plan Parcial de Sant Tomás des Migjorn Gran se adaptó a las Normas Subsidiarias, dándose en el caso una modificación puntual de este Plan Parcial de Sant Tomás des Migjorn Gran con toda la tramitación pertinente.

Tampoco prospera la impugnación indirecta de la Norma Territorial Transitoria adoptada el día 22 de diciembre de 2014 y publicada en el BOIB de 5 de enero de 2015 (ahora derogada). Esta Norma es también una disposición de carácter general autónoma y que no deriva del Plan Territorial Insular, sino que los desplaza y sustituye en algunos aspectos concretos. 
También aquí se argumentan defectos procedimentales sobre la falta de informes preceptivos en materia de Telecomunicaciones y de Defensa Nacional. En este caso el Tribunal recuerda que el 23 de diciembre de 2002 se requirió al Delegado del Gobierno la emisión de un informe sobre los ámbitos relativos a las competencias estatales afectadas, el cual fue evacuado el 24 de febrero de 2003. Dentro de esta petición, sostiene el Tribunal, se tienen que entender incluidos los aspectos concernientes a las telecomunicaciones y a la defensa nacional expresados en las normas mencionadas (Telecomunicaciones y Defensa Nacional). Este aspecto resulta muy relevante para marcar una línea jurisprudencial que indica un camino hacia la eficacia administrativa y la celeridad procedimental.

Con respecto al resto, la sentencia sigue desmontando todo el argumentario de la demanda, fundamentado en aspectos formales y de interconexión entre disposiciones que no responden a la lógica de nuestro sistema de normas. Es una sentencia de ámbito estrictamente procedimental relevando en algunos aspectos de la tramitación de instrumentos de ordenación territorial y urbanísticos.

\section{LA SENTENCIA DEL TRIBUNAL SUPERIOR DE JUSTICIA DE LAS ISLAS BALEARES NÚMERO 764/2018, DE 3 DE SEPTIEMBRE (ID. CENDOJ 07040330012018100434)}

El pleito arranca en una supuesta información errónea que proporcionó el Ayuntamiento de Sant Joan de Labritja (Eivissa) a los demandantes, una información que a la larga frustró una inversión y la transmisión de unas fincas. Ante estas circunstancias la parte perjudicada planteó una reclamación de responsabilidad patrimonial ante el mencionado Ayuntamiento.

El juzgado de instancia consideró que el asunto examinado se trataba de un supuesto no recogido en el artículo 35 del Texto Refundido de la Ley del Suelo de 2008, sino que se incardinara directamente en el artículo 106 de la Constitución. Igualmente no vio demostrado que el Ayuntamiento de Sant Joan de Labritja hubiera suministrado en la Demarcación de Costas una información sobre la clasificación del suelo que provocara que en la partición aprobada mediante el Orden Ministerial de 31 de diciembre de 2008 se incluyera una 
zona de servidumbre de protección de 100 metros que afectaba así en los terrenos propiedad de los actores, en lugar de los 20 metros que corresponden en el caso de afectar suelo urbano, de acuerdo con lo que establece la disposición transitoria tercera de la Ley de Costas.

La Sentencia razona que el Ayuntamiento siempre consideró el suelo como urbano y defendió que la servidumbre legal tenía que alcanzar 20 metros, constando así en el Proyecto de Delimitación de Suelo Urbano, en las alegaciones presentadas en el expediente de delimitación, en el informe emitido por el arquitecto municipal y en la aprobación provisional de las Normas Subsidiarias. De hecho, el Ayuntamiento había impugnado la mencionada delimitación de 2008 ante la Audiencia Nacional, atacando la extensión de la servidumbre de protección en 100 metros en determinados tramos de la línea de costa; esta impugnación fue desestimada en recurso contencioso mediante Sentencia de 16 de junio de 2011.

Por otra parte, no se considera acreditado que el contrato de compraventa quedara abortado a causa de las circunstancias invocadas ni que la sociedad propietaria de los terrenos se hubiera disuelto a causa de estos hechos. Por lo que el Juez de lo contencioso desestimó la demanda.

Ahora, en apelación, la demandante solicita la revocación de la sentencia de instancia, esgrimiendo los argumentos siguientes:

- Por la vulneración del derecho fundamental a la tutela judicial efectiva al haberse denegado la práctica de la prueba documental pública, del interrogatorio de parte en la persona del actual Alcalde de Sant Joan de Labritja y de la testifical del representante de ZEAR GRUPO INVERSIÓN INMOBILIARIA.

- Por la errónea valoración de la prueba practicada, ya que en el Orden Ministerial de 31 de diciembre de 2008 se indica que se incluye una servidumbre de protección de 100 metros de anchura en el tramo correspondiente a los terrenos de los actores, precisamente ante la información que se desprende del grado de consolidación a partir de los planos acompañados a los informes municipales de 17 de octubre y 11 de diciembre de 2007. 
- Por el hecho que el Ayuntamiento indujo a error a la Administración estatal, la cual reparó en esta irregularidad mediante el recurso de reposición planteado por los actores enfrente del acuerdo aprobatorio de la delimitación, siendo estimado mediante resolución dictada el 27 de septiembre de 2011.

- La actora considera que concurren los presupuestos necesarios para apreciar la responsabilidad patrimonial del Ayuntamiento, ya que los terrenos propiedad de los actores tenían sin duda la consideración de suelo urbano.

- Que este error en la delimitación provocada por el Ayuntamiento ocasionó daños y perjuicios en los actores, ya que el contrato de compraventa inicialmente negociado no se pudo ejecutar, ante la drástica reducción de la edificabilidad de las parcelas de los recurrentes, pasando de poder construir 85 viviendas en 10. Se imputa así la responsabilidad del Ayuntamiento por los daños presuntamente causados, ya que a pesar de la estimación del recurso de reposición, no modificó oportunamente las Normas Subsidiarias con el fin de adaptar el planeamiento a la delimitación de la servidumbre legal en 20 metros, habiendo sido solicitado el 2 de agosto de 2012.

- La lesión patrimonial ocasionada se valora en el informe pericial aportado con la demanda, de acuerdo con la disminución del valor cifrado en 584,28 euros/m2 edificable para uso residencial $\left(4.400 \mathrm{~m}^{2}\right.$ en EP1 y $4.100 \mathrm{~m}^{2}$ en EP2) y en 376,35 euros $/ \mathrm{m}^{2}$ edificable para uso comercial (908 $\mathrm{m}^{2}$ en EP1 y $1.035 \mathrm{~m}^{2}$ en EP2).

Por el contrario, la representación del Ayuntamiento solicita que se desestime el recurso de apelación argumentando que en todo momento el Ayuntamiento defendió que los terrenos situados entre los vértices 750 y 751 de la línea delimitada tenían la consideración de suelo urbano por consolidación. Eso implica que la línea que corresponde a la servidumbre de protección la tenía que ser de 20 metros, conforme a la plasmación gráfica del Proyecto de Delimitación del Suelo Urbano tramitado por la administración municipal. Así lo había acreditado, también, el Ayuntamiento mediante sendas alegaciones e informes presentados al expediente de delimitación del dominio público que 
tramitaba la Demarcación de Costas. De hecho el Ayuntamiento había impugnado el Orden Ministerial de 31 de diciembre de 2008 ante la jurisdicción contenciosa administrativa. El recurso. Sin embargo, fue desestimado por Sentencia de la Audiencia Nacional de 16 de junio de 2011, anterior a la resolución estimatoria del recurso de reposición.

Aunque el Consistorio defendiera esta clasificación urbanística y esta anchura de la servidumbre legal, en la aprobación de las normas subsidiarias, no tuvo más opción que cumplir las prescripciones impuestas por el Consejo Insular y por la Orden Ministerial de delimitación del DPM. Pero lo cierto es que hasta que el Ministerio no procedió a modificar la Orden Ministerial de 31 de diciembre de 2008, después de la resolución estimatoria del recurso de reposición, el Ayuntamiento no podía modificar, a su vez, las Normas Subsidiarias.

La clave de este pleito la encontramos en el fundamento de derecho segundo de la sentencia, que detalla una serie de datos de hecho que indican el camino a la resolución final del pleito:

"SEGUNDO. A fin de resolver las cuestiones controvertidas en el presente Rollo de Apelación, debemos destacar los siguientes datos de hecho que resultan relevantes:

1) $D^{\underline{a}}$ Miriam y $D$. Félix son propietarios de unos terrenos correspondientes a las fincas registrales no NUM000 y no NUM001 del Registro de la Propiedad número 1 de lbiza, con referencia catastral NUM002, ubicados en el tramo comprendido entre los vértices de deslinde 750-751 en el ámbito de Portinatx, dentro del término municipal de Sant Joan de Labritja (isla de Eivissa).

2) A la entrada en vigor de la Ley 22/1988, de 28 de julio de Costas (producida el 29 de julio de 1988), la ordenación urbanística del municipio se regía por el Plan General de Ordenación Urbana (PGOU) de 21 de noviembre de 1977, según el cual los terrenos de los actores estaban clasificados como suelo de reserva urbana a desarrollar mediante plan parcial, el cual nunca fue tramitado.

Este instrumento de planeamiento estuvo vigente hasta la revisión del planeamiento llevada a cabo en el año 2001. 
3) Tras la anulación judicial del Proyecto de Delimitación de Suelo Urbano (PDSU) de 17 de diciembre de 1990, el Ayuntamiento aprobó el 17 de febrero de 2005 un nuevo PDSU, el cual, desde su aprobación inicial, incluyó los terrenos de los actores en el suelo urbano y la servidumbre de protección se estableció a los 20 metros de la ribera del mar. La Dirección General de Costas emitió previo informe favorable.

4) El 31 de marzo y 17 de noviembre de 2006, el Ayuntamiento de Sant Joan de Labritja aprobó inicialmente la revisión del planeamiento mediante NNSS.

5) En enero del año 2007, la Dirección General de Costas reanudó la tramitación de un proyecto de deslinde del término municipal de Sant Joan de Labritja, iniciado en el año 1994, notificando esta incoación al Ayuntamiento el 14 de septiembre de 2007, confiriéndole un trámite de alegaciones respecto de la propuesta de deslinde. Según la documentación remitida, la franja de servidumbre de protección en los terrenos de los actores se había situado a 100 metros de la ribera del mar. El Ayuntamiento, en su escrito de 15 de octubre de 2007, se opuso al nuevo deslinde, entre otros motivos, porque defendía que la servidumbre de protección en los vértices 750-751 debía tener una extensión de 20 metros desde la ribera del mar, tal y como la Dirección General de Costas había considerado -implícitamente- en el informe remitido el 12 de enero de 2007 dentro del expediente municipal de elaboración de las NNSS, y de acuerdo con la jurisprudencia dictada en relación a la consideración de suelo urbano por consolidación de la urbanización o de la edificación (teoría sobre la fuerza normativa de lo fáctico).

El 17 de diciembre de 2007, el Ayuntamiento remitió a la Dirección General de Costas un escrito, adjuntando certificado de un informe confeccionado por el Arquitecto municipal, en el cual se concluyó que, conforme al Decreto 16/81 de 16 de octubre, los terrenos correspondientes al núcleo de Portinatx, entre otros, habían alcanzado la consolidación por alguno o por ambos requisitos (urbanización/edificación).

6) Las NNSS se aprobaron provisionalmente por el Ayuntamiento en fecha 21 de diciembre de 2007, manteniendo la clasificación de los terrenos de los actores como suelo urbano y situando la zona de servidumbre a los 20 metros de la ribera del mar.

7) El deslinde fue aprobado por Orden Ministerial de 31 de diciembre de 2008, siendo publicado el anuncio en el BOE $n^{\circ}$ 31, de 5 de febrero de 
2009. La anchura de la servidumbre de protección en las fincas titularidad de los aquí actores y apelantes era de 100 metros, quienes el 5 de marzo siguiente interpusieron recurso de reposición ante el Ministerio de Medio Ambiente, Medio Rural y Marino.

8) La incorporación de esta línea de deslinde en el proyecto de NNSS se produjo tras la sesión de la Comisión Insular de Ordenación del Territorio, Urbanismo y Patrimonio Histórico-Artístico (CIOTUPHA) del Consell Insular d'Eivissa de día 3 de marzo de 2009, en la cual se acordó suspender la aprobación definitiva de las NNSS, exigiendo en el punto 4 la necesidad de adaptar las servidumbres de protección O.M. de 31 de diciembre de 2.008, obligando a un nuevo trámite de información pública, iniciado el 17 de octubre de 2009, y en cuyo seno el Sr. Félix presentó alegaciones referentes a la materialización de la densidad máxima en la UA-4PO (90 viviendas) en el supuesto de que se mantuviese o revocase por el Ministerio la anchura de la servidumbre en 100 metros. Esta alegación fue desestimada por acuerdo plenario de 12 de febrero de 2010, al implicar una modificación de las NNSS en el supuesto que se estimara el recurso de reposición frente al acuerdo de deslinde.

9) La revisión del planeamiento mediante NNSS fue aprobada definitivamente -con prescripciones y suspendida en determinados aspectos- mediante acuerdo adoptado el 29 de abril de 2011 por la CIOTUPHA, publicado en el BOIB $n^{\circ}$ 123, de 7 de julio de 2011, el cual no fue impugnado ni por los actores ni por la entidad "Zear Grupo Inmobiliario", deviniendo firme con la distancia de la servidumbre de protección a los 100 metros.

10) El Ayuntamiento de Sant Joan de Labritja formuló recurso contenciosoadministrativo contra la O.M. de 31 de diciembre de 2008 (Procedimiento Ordinario no 200/2009 de la Sección 1a de la Sala de la Audiencia Nacional), el cual fue desestimado por Sentencia dictada el 16 de junio de 2011.

11) El recurso de reposición formulado por los Sres. Félix contra el acuerdo de deslinde fue estimado mediante resolución adoptada por la Ministra del ramo (actuando por delegación la Secretaria General Técnica) el día 27 de septiembre de 2011, al considerar demostrado que -en la fecha de entrada en vigor de la Ley de Costas- sus parcelas contaban con los servicios necesarios para ser clasificados como urbanos, basándose, entre otros 
documentos, en el certificado municipal expedido el 14 de abril de 2011, el cual así lo expresaba.

En el Fundamento de Derecho B) de la resolución estimando el recurso de reposición, se menciona la Consideración Tercera y el Antecedente VIII de la Orden Ministerial recurrida, del modo que se transcribe:

"B) Los terrenos de los que son titulares los recurrentes se encuentran ubicados en el tramo comprendido entre los vértices de deslinde 750-751, en el ámbito de Portinatx, del término municipal de de Sant Joan de Labritja. En el planeamiento urbanístico que se encontraba vigente a la entrada en vigor de la vigente Ley de Costas, que era el Plan General de Ordenación Urbana de 1977, dichos terrenos se encontraban incluidos en el suelo de reserva urbana, no contando con Plan Parcial aprobado, y sin que, tal y como se hace constar la Consideración Tercera de la Orden impugnada, pudieran ser considerados incluidos dentro del área consolidada por la edificación, en base a los informes emitidos en el año 2007 por el Ayuntamiento de Sant Joan de Labritja especificados en el Antecedente VIII de la Orden aprobatoria del deslinde."

12) La contradicción existente entre la resolución estimatoria del recurso de reposición (favorable a situar la distancia de la servidumbre de protección a los 20 metros), y la Sentencia de la Audiencia Nacional (en la cual se desestima que deba anularse la línea de deslinde en cuanto fija la servidumbre en 100 metros, manteniendo lo dispuesto en la O.M.), no fue solventada hasta la resolución emitida el 14 de mayo de 2013 por la Dirección General de Costas [publicada en el BOIB no 88 de 22 de junio de 2013], siguiendo la decisión de la resolución estimatoria del recurso de reposición.

13) El 5 de mayo de 2006, la mercantil "Inmobiliaria Portinatx S.L." (siendo socios los actores) y la sociedad "Zear Grupo de Inversión Inmobiliaria, S.A." suscribieron una promesa bilateral de venta de las dos fincas registrales, señalando como plazo 15 meses desde su firma para suscribir el contrato de compraventa, el cual finalizaba el 5 de agosto de 2007. El 29 de junio de 2007, se disolvió la mercantil vendedora, iniciándose período de liquidación. El 2 de agosto de 2007 se firmó el contrato privado de compraventa, pero sin que se formalizase en escritura pública en el plazo fijado como condición resolutoria, antes del 1 de diciembre de 2007. El 21 
de diciembre de 2007, tras la liquidación de la sociedad, se adjudicó la propiedad de los terrenos a los Sres. Félix.»

A la vista de esta exposición el Tribunal trata la cuestión central del pleito: si se puede desprender de todo eso que existiera una actuación municipal que hubiera producido efectos lesivos en el patrimonio de los Sres. Félix que motiven acordar la existencia de un supuesto de responsabilidad patrimonial.

El Tribunal determina que se tiene que rechazar la petición de responsabilidad patrimonial a partir del relato de hechos consignado en el Fundamento Segundo de la Sentencia. Y lo hace sobre la base de los argumentos siguientes:

«En primer lugar, el contrato de compraventa de las dos fincas registrales lindantes con los vértices 750 y 751 del deslinde, quedó resuelto por no elevarse el contrato privado suscrito el 2 de agosto de 2007 a escritura pública antes del 1 de diciembre de 2007, y ello por motivos que no constan a esta Sala, pero que en todo caso fueron anteriores a la aprobación de la O. M. de 31 de diciembre de 2008.

En segundo lugar, la disolución de la entidad propietaria y vendedora devino en junio de 2007, y su liquidación efectiva en fecha 21 de diciembre de 2007, siendo anteriores a la aprobación ministerial de la línea de deslinde con una extensión de la servidumbre de protección en 100 metros, en lugar de 20 metros.

En tercer lugar, porque resulta claramente constatado que el Ayuntamiento, tanto en el expediente de deslinde, como en el procedimiento de revisión del planeamiento, siempre defendió que los terrenos propiedad de los actores debían ser considerados como urbanos por consolidación de los servicios básicos, y que, consiguientemente, la servidumbre de protección debía tener una anchura de 20 metros, de acuerdo con la disposición transitoria tercera de la Ley de Costas.

A partir de la O.M. de 31 de diciembre de 2008 y de la resolución de 27 de septiembre de 2011, estimatoria del recurso de reposición formulado por los actores contra el deslinde, no se desprende que la Administración competente en materia de demanio marítimo-terrestre fijase la servidumbre en 100 metros a causa de los informes desfavorables emitidos por el Consistorio, sino que se colige que el Ministerio señaló la citada anchura al interpretar los documentos remitidos por el Ayuntamiento, ya que la 
Administración estatal apreció que no tenían la consideración de suelo urbano a resultas de los datos que expresaba esta documentación, sin que en ningún caso el Ayuntamiento, directa ni implícitamente, se hubiese posicionado en contra de esta clasificación urbanística, sino todo lo contrario, siempre mantuvo un comportamiento defensor del carácter urbano de las parcelas y de establecer una extensión de 20 metros de la citada servidumbre legal.»

Toda esta línea argumental conduce al Tribunal de apelación a desestimar el recurso y confirmar la sentencia del Juzgado del Contencioso impugnada. Se considera que la situación básica del suelo no tenía la consideración de suelo urbano y por este motivo, y a la vista de la documentación que se encontraba en poder de la Demarcación de Costas, la servidumbre se situó en 100 metros (y no en veinte). Por lo que no hay ninguna responsabilidad del ayuntamiento y la vía que correspondía era impugnar la Orden Ministerial aprobada. 


\title{
JURISPRUDENCIA AMBIENTAL EN LAS ISLAS BALEARES
}

(SEGUNDO SEMESTRE 2018)

\author{
Josep Manuel Gómez GonzÁlez \\ Departamento de Territorio e Infraestructuras \\ Consejo Insular de Mallorca \\ jmgomez@conselldemallorca.net
}

\begin{abstract}
Sumari: 1. Introducció. 2. Els defectes de tramitació de disposicions territorials i la via de les impugnacions indirectes: la sentència del Tribunal Superior de Justícia de les Illes Balears número 752/2018, de 17 de juliol (ID. Cendoj 07040330012018100427). 3. Sobre la responsabilitat patrimonial derivada de la protecció ambiental de costes. La sentència del Tribunal Superior de Justícia de les Illes Balears número 764/2018, de 3 de setembre (Id.. Cendoj 07040330012018100434).
\end{abstract}

\section{INTRODUCCIÓ}

La jurisprudència ambiental d'aquest semestre torna a destacar per l'absència de casos destacables en matèria ambiental i territorial. Així, aquesta revisió se centra en dos assumptes eminentment procedimentals que són rellevants, precisament, amb relació a possibles defectes de tramitació de sengles disposicions normatives.

D'una banda tenim una sentència amb relació a la impugnació d'una bateria d'instruments d'ordenació territorial i urbanístiques on la demandant intenta aplicar la doctrina desplegada amb relació a la connexió d'actes administratius especialment vinculats amb la finalitat d'aconseguir una cadena d'impugnacions indirectes amb el consegüent efecte d'anul-lació de disposicions derivades jeràrquicament, Això ho fem amb l'anàlisi de la sentència del Tribunal Superior de Justícia de les llles Balears número 752/2018, de 17 de juliol. També analitzarem un cas de responsabilitat patrimonial derivada de la protecció ambiental de costes amb relació a la fiabilitat de la informació proporcionada per un ajuntament sobre una matèria que ateny la delimitació del domini públic estatal de costes. Això, serà amb la sentència del Tribunal Superior de Justícia de les Illes Balears número 764/2018, de 3 de setembre. 


\section{ELS DEFECTES DE TRAMITACIÓ DE DISPOSICIONS TERRITORIALS I} LA VIA DE LES IMPUGNACIONS INDIRECTES, LA SENTĖNCIA DEL TRIBUNAL SUPERIOR DE JUSTÍCIA DE LES ILLES BALEARS NÚMERO 752/2018, DE 17 DE JULIOL (ID. CENDOJ 070403300120118100427)

L'objecte del plet és la impugnació, d'una banda, de l'acord del Ple del Consell Insular de Menorca, adoptat en sessió celebrada el 21 de setembre de 2015, pel qual es va aprovar definitivament la modificació puntual del Sector $\mathrm{C}$ del Pla Parcial de Sant Tomás des Migjorn Gran (Menorca); i d'una altra banda, la impugnació de la sentència de la Sala núm. 1121, de 20/12/2010, més concretament la impugnació indirecta de l'assenyalada sentència per entendre que és nul-la de ple dret. Amb aquesta maniobra es pretén aconseguir que la resolució de la Sala, arrossegui la seva nul-litat en cadena de tots els actes vinculats, en deixar-los sense sosteniment jurídic. Per tant, es persegueixen per la via indirecta tots aquells acords del Consell Insular de Menorca vinculats amb la sentència, de manera que es generi una reacció d'invalidesa en cadena. En detall, la demanda, segons recull la sentència sol-licitava:

«SEGUNDO.- La demanda se formalizó en plazo legal. Se solicitó entonces el recibimiento del juicio a prueba "[...] sobre cualquier punto que sea negado de adverso y sobre cualquier informe que haya sido emitido en el pleito, aportado o alegado por la Administración demandada, y, en especial se señalan como prueba, los documentos que acompañan al presente escrito que, de no ser aceptadas como tales las copias aportadas, se provea lo pertinente". Y se solicitaba también, además de la estimación del recurso y la imposición de las costas del juicio, que la sentencia de la Sala declare:

"[...] no ser conforme a derecho las siguientes resoluciones impugnadas:

1ํㅡㄹ Directamente, la "MODIFICACIÓN PUNTUAL DEL SECTOR C DEL PLAN PARCIAL DE SANT TOMÁS DE ES MIGJORN GRAN" (Exp. NUM000 )."

2ำ Indirectamente, la de "APROBACIÓN DEFINITIVA DEL PLAN 'TERRITORIAL INSULAR DE MENORCA", adoptado en la sesión extraordinaria de fecha 25 de abril de 2003 (publicado en el BOIB núm. 69 EXT, de 16 de mayo de 2003), de conformidad con lo dispuesto el artículo 27.2 de la U. 
$3^{\circ}$ Indirectamente, la de "LEVANTAMIENTO DE LA SUSPENSIÓN ACORDADA RESPECTO AL INICIO DE LA EFICACIA DE LAS DETERMINACIONES DEL PLAN TERRITORIAL INSULAR DE MENORCA, RELATIVAS AL LITORAL" adoptado el 27 de octubre de 2003 (publicado en el BOIB $n^{\circ} 155$, de 8 de noviembre de 2003, de conformidad con lo dispuesto el artículo 27.2 de la LJ, si procede, en el supuesto de ser admitida la impugnación indirecta aquí instada contra Aprobación Definitiva del Plan Territorial Insular de Menorca, en la que fundamentaba su soporte jurídico.

$4^{\circ}$ Indirectamente, la de "RECTIFICACIÓN DE ERRORES DEL PLAN TERRITORIAL INSULAR DE MENORCA", adoptado en la sesión ordinaria de 27 de octubre de 2003 (publicado en el BOIB n 158 EXT, de 14 de noviembre de 2003), de conformidad con lo dispuesto el artículo 27.2 de la LJ, si procede, en el supuesto de ser admitida la impugnación indirecta aquí instada contra Aprobación Definitiva del Plan Territorial Insular de Menorca, en la que fundamentaba su soporte jurídico.

$5^{\circ}$ Indirectamente, la de "APROBACIÓN DEFINITIVA DE LA MODIFICACION DEL PLAN TERRITORIAL INSULAR DE MENORCA", adoptado en la sesión ordinaria de 26 de junio de 2006 (publicado en el BOIB n 155, de 27 de julio de 2006, de conformidad con lo dispuesto el artículo 27.2 de la LJ, si procede, en el supuesto de ser admitida la impugnación indirecta aquí instada contra Aprobación Definitiva del Plan Territorial Insular de Menorca, en la que fundamentaba su soporte jurídico"».

La defensa de la administració insular destaca el fet que el recurs té per objecte actes no susceptibles d'impugnació, recau sobre cosa jutjada i s'ha presentat l'escrit inicial fora del termini establert. Per sostenir això invoca l'article 28 de la Llei Jurisdiccional quant a l'acte confirmatori i a l'admissibilitat del recurs. Concretament les peticions són:

«Las Sentencias de 11 de septiembre de 1991, 30 de marzo de 1992, 2 de marzo y 25 de octubre de 1993, 22 de enero, 7 de julio y 22 de enero y 25 de octubre de 1994 y 7 de marzo de 1995 del Tribunal Supremo, sobre desviación procesal". 
Por lo tanto, el Consell Insular de Menorca solicitaba en su contestación a la demanda que en la sentencia de la Sala:

«1.- Se declare la inadmisibilidad del recurso respecto a la aprobación definitiva el PTIMe, al levantamiento de la suspensión acordada respecto al inicio de la eficacia de las determinaciones del PTIMe, relativas al litoral, la rectificación de errores del PTIMe y la aprobación definitiva de la modificación del PTIMe.

2.-Acuerde la desestimación del recurso contencioso-administrativo respecto al acuerdo de 21 de septiembre de 2011, adoptado por el Pleno del Consell Insular de Menorca por el que se resolvió aprobar definitivamente la modificación puntual del Plan Parcial del Sector C de Sant Tomás de Es Migjorn Gran,confirmando en todas sus partes el acto objeto de recurso.»

S'ha de destacar que en l'escrit d'interposició del recurs contenciós administratiu, el demanant el dirigia únicament contra l'acord del Ple del Consell Insular de Menorca pel qual es va aprovar definitivament la modificació puntual del Sector C del Pla Parcial de Sant Tomás des Migjorn Gran. La resta d'impugnacions indirectes provenen d'un gir argumental plantejat ja en seu de formalització de la demanda.

Igualment, la part actora denuncia l'omissió de tres tràmits essencials en el procediment d'elaboració de la disposició general, erigint aquesta mancada com a causa de nul-litat de ple dret, però ho planteja com si l'acord impugnat fos un acte administratiu i no una disposició normativa. Per això, el Tribunal ha d'aclarir que les irregularitats procedimentals denunciades no es poden inserir com a infraccions dels preceptes de la Llei 30/1992, de 26 de novembre, ja que el mateix es refereix al procediment d'aprovació d'actes administratius, mentre que en l'assumpte analitzat, ens trobem davant un reglament o disposició general.

Per això, ja s'avança que l'absència dels informes preceptius i, si s'escau, vinculants, a emetre pels òrgans de l'Administració Estatal, es tractaria d'una vulneració del principi de jerarquia normativa, pel fet que el Consell Insular de Menorca no hagués donat compliment a certes determinacions contingudes en diferents Ileis sectorials. En concret, la Llei 22/1988, de 28 de juliol, de Costas, 
la Llei 11/1998, de 24 d'abril, General de Telecomunicacions i Llei 6/1998, de 13 d'abril, de Règim del Sòl i Valoracions (vigents aleshores).

Amb tot, consten al procediment les peticions dels informes sectorials assenyalats, com ara l'ofici remès per la Consellera-Delegada d'Ordenació del Territori, Urbanisme i Medi Ambient dirigit a la Direcció General de Costas, el 18 de novembre de 2002, en el qual s'interessa l'emissió de l'informe exigit en l'article 117.1 de la Llei de Costas. D'altra banda la petició va ser cursada en la mateixa data tant al Ministeri de Medi Ambient com a la Delegació del Govern de l'Estat a les Illes Balears.

Sobre aquesta qüestió formal s'ha de destacar el fet que el 18 de febrer de 2003, la Unitat de Suport-Planejament Urbanístic pertanyent a la Direcció General de Costas va confeccionar l'informe -preceptiu i vinculant- establert en els articles 112 i 117.1 de la Llei de Costas, consignant una sèrie d'observacions a tenir en compte en l'aprovació definitiva.

També, el 27 de febrer de 2003 es va rebre un informe redactat pel Delegat del Govern sobre les qüestions que atenyen a matèries de competència estatal, contenint una sèrie d'observacions sobre energia, declaracions d'interès general en agricultura i medi ambient, aigües marines, costes, zona portuària i aeroportuària, $\mathrm{i}$, en el punt 9 , es va recollir que «Haurà de contemplar la normativa específica de les zones declarades d'interès per a la defensa nacional i delimitar sobre pla els terrenys, edificacions $i$ instal-lacions, incloses les seves zones de protecció, afectes a la Defensa Nacional.»

Davant aquesta resposta, el 19 de març de 2003, la Presidenta del Consell Insular va comunicar al Delegat del Govern que les observacions no eren substancials i que s'havien recollit en el text definitiu, interessant la celebració d'una reunió, la qual va tenir lloc el 26 de març següent.

Finalment, el 25 d'abril de 2003, el Ple del Consell Insular va aprovar el Pla Territorial de l'llla de Menorca, en el qual es va consignar una norma temporal i condicional relativa a la suspensió de l'eficàcia de les prescripcions referents al litoral, fins que es rebés l'informe favorable establert en l'article 117.2 de la Llei de Costas. Rebut l'informe positiu, el Ple va alçar la suspensió de la vigència de tals articles el 27 d'octubre de 2003 (BOIB núm. 155, de 8 de novembre). 
Per tot això, la impugnació indirecta del Pla Territorial Insular de Menorca, decau. I és que, mancant resposta del demandant a la pretensió d'inadmissió del recurs que figura en les dues contestacions a la demanda, el Tribunal considera que, independentment que la impugnació indirecta de la sentència de la Sala núm. 1121/2010 no s'inclogués en l'escrit d'interposició del recurs sinó s'hagi afegit després, concretament en la demanda, en definitiva, aquesta impugnació recau sobre cosa jutjada. Així es considera que s'incorre en la causa d'inadmissió recollida en l'article 69. d) de la Llei 29/1998.

Igual fortuna obté la impugnació de acord del Ple del Consell Insular de Menorca, adoptat en sessió de 21 de setembre de 2015, pel qual es va aprovar definitivament la modificació puntual del Sector C del Pla Parcial de Sant Tomás des Migjorn Gran. Aquí, el demandant insisteix que en l'elaboració del Pla Territorial Insular de Menorca va faltar l'informe preceptiu de l'art. 117.2 de la Llei de Costas; però el Tribunal manté sobre aquest tema: per un costat, que ja consta que en ocasió de l'adaptació del Pla Parcial a les Normes Subsidiàries es va sol-licitar l'informe de Costas; per un altre costat, que també consta que aquest informe va ser emès en sentit favorable, justament perquè el Sector C, que era el més allunyat del litoral, en definitiva, no comptava amb cap mena d'afectació de la Llei de Costas. Per tot això, l'acord d'aprovar definitivament la modificació puntual del Pla Parcial del Sector C de Sant Tomás des Migjorn Gran, malgrat l'adduït en la demanda, és conforme a Dret.

Però és que a més, el Tribunal recorda a la demandant que la modificació puntual del Pla Parcial de Sant Tomás des Migjorn Gran no s'ha dictat en aplicació del Pla Territorial Insular de Menorca sinó que es dicta en aplicació de les Normes Subsidiàries des Migjorn Gran. En efecte, adaptades les Normes Subsidiàries des Migjorn Gran al Pla Territorial Insular de Menorca, posteriorment el Pla Parcial de Sant Tomás des Migjorn Gran es va adaptar a les Normes Subsidiàries, donant-se en el cas una modificació puntual d'aquest Pla Parcial de Sant Tomás des Migjorn Gran amb tota la tramitació pertinent.

Tampoc prospera la impugnació indirecta de la Norma Territorial Transitòria adoptada el dia 22 de desembre de 2014 i publicada en el BOIB de 5 de gener de 2015 (ara derogada). Aquesta Norma és també una disposició de caràcter 
general autònoma i que no deriva del Pla Territorial Insular, sinó que els desplaça i substitueix en alguns aspectes concrets.

També aquí s'argumenten defectes procedimentals sobre la manca d'informes preceptius en matèria de Telecomunicacions i de Defensa Nacional. En aquest cas el Tribunal recorda que el 23 de desembre de 2002 es va requerir del Delegat del Govern l'emissió d'un informe sobre els àmbits relatius a les competències estatals afectades, el qual va ser evacuat el 24 de febrer de 2003. Dins aquesta petició, sosté el Tribunal, s'han d'entendre inclosos els aspectes concernents a les telecomunicacions i a la defensa nacional expressats en les normes esmentades (Telecomunicacions i Defensa Nacional). Aquest aspecte resulta molt rellevant per marcar una línia jurisprudencial que indica un camí cap a l'eficàcia administrativa i la celeritat procedimental.

Pel que fa a la resta, la sentència segueix desmuntant tot l'argumentari de la demanda, fonamentat en aspectes formals i de interconnexió entre disposicions que no responen a la lògica del nostre sistema de normes. És una sentència d'àmbit estrictament procedimental rellevant en alguns aspectes de la tramitació de instruments d'ordenació territorial i urbanístics.

\section{LA SENTĖNCIA DEL TRIBUNAL SUPERIOR DE JUSTÍCIA DE LES ILLES BALEARS NÚMERO 764/2018, DE 3 DE SETEMBRE (ID. CENDOJ 07040330012018100434)}

El plet arrenca en una suposada informació errònia que va proporcionar l'Ajuntament de Sant Joan de Llabritja (Eivissa) als demandants, una informació que a la llarga va frustrar una inversió i la transmissió d'unes finques. Davant aquestes circumstàncies la part perjudicada va plantejar una reclamació de responsabilitat patrimonial davant l'assenyalat Ajuntament.

El jutjat d'instància va considerar que l'assumpte examinat es tractava d'un supòsit no recollit en l'article 35 del Text Refós de la Llei del Sòl de 2008, sinó que s'incardinava directament en l'article 106 de la Constitució. Igualment no va veure demostrat que l'Ajuntament de Sant Joan de Labritja hagués subministrat a la Demarcació de Costas una informació sobre la classificació del sòl que 
provoqués que en la partió aprovada mitjançant l'Ordre Ministerial de 31 de desembre de 2008 s'inclogués una zona de servitud de protecció de 100 metres que afectava així als terrenys propietat dels actors, en lloc dels 20 metres que corresponen als supòsits de sòl urbà, d'acord amb el que estableix la disposició transitòria tercera de la Llei de Costas.

La Sentència raona que l'Ajuntament sempre va considerar el sòl com a urbà i va defensar que la servitud legal havia d'atènyer 20 metres, constant així en el Projecte de Delimitació de Sòl Urbà, en les al-legacions presentades en l'expedient de delimitació, en l'informe emès per l'arquitecte municipal i en l'aprovació provisional de les Normes Subsidiàries. De fet, l'Ajuntament havia impugnat l'esmentada delimitació de 2008 davant l'Audiència Nacional, atacant l'extensió de la servitud de protecció en 100 metres en determinats trams de la línia de costa; aquesta impugnació va ser desestimada en recurs contenciós mitjançant Sentència de 16 de juny de 2011.

D'altra banda, no es considera acreditat que el contracte de compravenda quedés avortat a causa de les circumstàncies invocades ni que la societat propietària dels terrenys s'hagués dissolt a causa d'aquests fets. Per la qual cosa el Jutge del contenciós va desestimar la demanda.

Ara, en apel-lació, la demandant sol-licita la revocació de la sentència d'instància, esgrimint els arguments següents:

Per la vulneració del dret fonamental a la tutela judicial efectiva en haver-se denegat la pràctica de la prova documental pública, de l'interrogatori de part en la persona de l'actual Alcalde de Sant Joan de Labritja i de la testifical del representant de ZEAR GRUP INVERSIÓ IMMOBILIÀRIA.

Per l'errònia valoració de la prova practicada, ja que en l'Ordre Ministerial de 31 de desembre de 2008 s'indica que s'inclou una servitud de protecció de 100 metres d'amplària en el tram corresponent als terrenys dels actors, precisament davant la informació que es desprèn del grau de consolidació a partir dels plànols acompanyats als informes municipals de 17 d'octubre i 11 de desembre de 2007. 
Pel fet que l'Ajuntament va induir a error a l'Administració estatal, la qual va reparar en aquesta irregularitat mitjançant el recurs de reposició plantejat pels actors enfront de l'acord aprovatori de la delimitació, sent estimat mitjançant resolució dictada el 27 de setembre de 2011.

L'actora considera que concorren els pressupostos necessaris per a apreciar la responsabilitat patrimonial de l'Ajuntament, ja que els terrenys propietat dels actors tenien sens dubte la consideració de sòl urbà.

Que aquesta errada en la delimitació provocada per l'Ajuntament va ocasionar danys i perjudicis en els actors, ja que el contracte de compravenda inicialment negociat no es va poder executar, davant la dràstica reducció de l'edificabilitat de les parcel-les dels recurrents, passant de poder construir 85 habitatges a 10. S'imputa així la responsabilitat de l'Ajuntament pels danys presumptament causats, ja que malgrat l'estimació del recurs de reposició, no va modificar oportunament les Normes Subsidiàries a fi d'adaptar el planejament a la delimitació de la servitud legal en 20 metres, havent estat sol-licitat el 2 d'agost de 2012.

La lesió patrimonial ocasionada es valora en l'informe pericial aportat amb la demanda, d'acord amb la disminució del valor xifrat en 584,28 euros/m2 edificable per a ús residencial $(4.400 \mathrm{~m} 2$ en EP1 i $4.100 \mathrm{~m} 2$ en EP2) i en 376,35 euros/m2 edificable per a ús comercial (908 m2 en EP1 i 1.035 m2 en EP2).

Per contra, la representació de l'Ajuntament sol-licita que es desestimi el recurs d'apel-lació argumentant que en tot moment l'Ajuntament va defensar que els terrenys situats entre els vèrtexs 750 i 751 de la línia delimitada tenien la consideració de sòl urbà per consolidació. Això implica que la línia que correspon a la servitud de protecció la havia de ser de 20 metres, conforme a la plasmació gràfica del Projecte de Delimitació del Sòl Urbà tramitat per l'administració municipal. Així ho havia acreditat, també, l'Ajuntament mitjançant sengles al-legacions i informes presentats a l'expedient de delimitació del domini públic que tramitava la Demarcació de Costas. De fet l'Ajuntament havia impugnat l'Ordre Ministerial de 31 de desembre de 2008 davant la jurisdicció contenciosa administrativa. El recurs. Però, va ser 
desestimat per Sentència de l'Audiència Nacional de 16 de juny de 2011, anterior a la resolució estimatòria del recurs de reposició.

Tot i que el Consistori defensés aquesta classificació urbanística i aquesta amplària de la servitud legal, en l'aprovació de les normes subsidiàries, no va tenir més opció que complir les prescripcions imposades pel Consell Insular i per l'Ordre Ministerial de delimitació del DPM. Però el cert és que fins que el Ministeri no va modificar l'Ordre Ministerial de 31 de desembre de 2008, després de la resolució estimatòria de la reposició, I'Ajuntament no podia modificar, al seu torn, les Normes Subsidiàries.

La clau d'aquest plet la trobem al fonament de dret segon de la sentència, que detalla una sèrie de dades de fet que indiquen el camí a la resolució final del plet:

«SEGUNDO. A fin de resolver las cuestiones controvertidas en el presente Rollo de Apelación, debemos destacar los siguientes datos de hecho que resultan relevantes:

1) Da Miriam y D. Felix son propietarios de unos terrenos correspondientes a las fincas registrales no NUM000 y no NUM001 del Registro de la Propiedad número 1 de Ibiza, con referencia catastral NUM002, ubicados en el tramo comprendido entre los vértices de deslinde 750-751 en el ámbito de Portinatx, dentro del término municipal de Sant Joan de Labritja (isla de Eivissa).

2) A la entrada en vigor de la Ley $22 / 1988$, de 28 de julio de Costas (producida el 29 de julio de 1988), la ordenación urbanística del municipio se regía por el Plan General de Ordenación Urbana (PGOU) de 21 de noviembre de 1977, según el cual los terrenos de los actores estaban clasificados como suelo de reserva urbana a desarrollar mediante plan parcial, el cual nunca fue tramitado.

Este instrumento de planeamiento estuvo vigente hasta la revisión del planeamiento llevada a cabo en el año 2001.

3) Tras la anulación judicial del Proyecto de Delimitación de Suelo Urbano (PDSU) de 17 de diciembre de 1990, el Ayuntamiento aprobó el 17 de febrero de 2005 un nuevo PDSU, el cual, desde su aprobación inicial, incluyó los terrenos de los actores en el suelo urbano y la servidumbre de protección se 
estableció a los 20 metros de la ribera del mar. La Dirección General de Costas emitió previo informe favorable.

4) El 31 de marzo y 17 de noviembre de 2006, el Ayuntamiento de Sant Joan de Labritja aprobó inicialmente la revisión del planeamiento mediante NNSS.

5) En enero del año 2007, la Dirección General de Costas reanudó la tramitación de un proyecto de deslinde del término municipal de Sant Joan de Labritja, iniciado en el año 1994, notificando esta incoación al Ayuntamiento el 14 de septiembre de 2007, confiriéndole un trámite de alegaciones respecto de la propuesta de deslinde. Según la documentación remitida, la franja de servidumbre de protección en los terrenos de los actores se había situado a 100 metros de la ribera del mar.

El Ayuntamiento, en su escrito de 15 de octubre de 2007, se opuso al nuevo deslinde, entre otros motivos, porque defendía que la servidumbre de protección en los vértices 750-751 debía tener una extensión de 20 metros desde la ribera del mar, tal y como la Dirección General de Costas había considerado -implícitamente- en el informe remitido el 12 de enero de 2007 dentro del expediente municipal de elaboración de las NNSS, y de acuerdo con la jurisprudencia dictada en relación a la consideración de suelo urbano por consolidación de la urbanización o de la edificación (teoría sobre la fuerza normativa de lo fáctico).

El 17 de diciembre de 2007, el Ayuntamiento remitió a la Dirección General de Costas un escrito, adjuntando certificado de un informe confeccionado por el Arquitecto municipal, en el cual se concluyó que, conforme al Decreto 16/81 de 16 de octubre, los terrenos correspondientes al núcleo de Portinatx, entre otros, habían alcanzado la consolidación por alguno o por ambos requisitos (urbanización/edificación).

6) Las NNSS se aprobaron provisionalmente por el Ayuntamiento en fecha 21 de diciembre de 2007, manteniendo la clasificación de los terrenos de los actores como suelo urbano y situando la zona de servidumbre a los 20 metros de la ribera del mar. 
7) El deslinde fue aprobado por Orden Ministerial de 31 de diciembre de 2008, siendo publicado el anuncio en el BOE № 31, de 5 de febrero de 2009. La anchura de la servidumbre de protección en las fincas titularidad de los aquí actores y apelantes era de 100 metros, quienes el 5 de marzo siguiente interpusieron recurso de reposición ante el Ministerio de Medio Ambiente, Medio Rural y Marino.

8) La incorporación de esta línea de deslinde en el proyecto de NNSS se produjo tras la sesión de la Comisión Insular de Ordenación del Territorio, Urbanismo y Patrimonio Histórico-Artístico (ClOTUPHA) del Consell Insular d'Eivissa de día 3 de marzo de 2009, en la cual se acordó suspender la aprobación definitiva de las NNSS, exigiendo en el punto 4 la necesidad de adaptar las servidumbres de protección O.M. de 31 de diciembre de 2.008, obligando a un nuevo trámite de información pública, iniciado el 17 de octubre de 2009, y en cuyo seno el Sr. Felix presentó alegaciones referentes a la materialización de la densidad máxima en la UA-4P0 (90 viviendas) en el supuesto de que se mantuviese o revocase por el Ministerio la anchura de la servidumbre en 100 metros. Esta alegación fue desestimada por acuerdo plenario de 12 de febrero de 2010, al implicar una modificación de las NNSS en el supuesto que se estimara el recurso de reposición frente al acuerdo de deslinde.

9) La revisión del planeamiento mediante NNSS fue aprobada definitivamente con prescripciones y suspendida en determinados aspectos- mediante acuerdo adoptado el 29 de abril de 2011 por la CIOTUPHA, publicado en el BOIB no 123, de 7 de julio de 2011, el cual no fue impugnado ni por los actores ni por la entidad "Zear Grupo Inmobiliario", deviniendo firme con la distancia de la servidumbre de protección a los 100 metros.

10) El Ayuntamiento de Sant Joan de Labritja formuló recurso contenciosoadministrativo contra la O.M. de 31 de diciembre de 2008 (Procedimiento Ordinario no 200/2009 de la Sección $1^{\text {a }}$ de la Sala de la Audiencia Nacional), el cual fue desestimado por Sentencia dictada el 16 de junio de 2011.

11) El recurso de reposición formulado por los Sres. Felix contra el acuerdo de deslinde fue estimado mediante resolución adoptada por la Ministra del ramo 
(actuando por delegación la Secretaria General Técnica) el día 27 de septiembre de 2011, al considerar demostrado que -en la fecha de entrada en vigor de la Ley de Costas- sus parcelas contaban con los servicios necesarios para ser clasificados como urbanos, basándose, entre otros documentos, en el certificado municipal expedido el 14 de abril de 2011, el cual así lo expresaba.

En el Fundamento de Derecho B) de la resolución estimando el recurso de reposición, se menciona la Consideración Tercera y el Antecedente VIII de la Orden Ministerial recurrida, del modo que se transcribe:

"B) Los terrenos de los que son titulares los recurrentes se encuentran ubicados en el tramo comprendido entre los vértices de deslinde 750-751, en el ámbito de Portinatx, del término municipal de de Sant Joan de Labritja. En el planeamiento urbanístico que se encontraba vigente a la entrada en vigor de la vigente Ley de Costas, que era el Plan General de Ordenación Urbana de 1977, dichos terrenos se encontraban incluidos en el suelo de reserva urbana, no contando con Plan Parcial aprobado, y sin que, tal y como se hace constar la Consideración Tercera de la Orden impugnada, pudieran ser considerados incluidos dentro del área consolidada por la edificación, en base a los informes emitidos en el año 2007 por el Ayuntamiento de Sant Joan de Labritja especificados en el Antecedente VIII de la Orden aprobatoria del deslinde."

12) La contradicción existente entre la resolución estimatoria del recurso de reposición (favorable a situar la distancia de la servidumbre de protección a los 20 metros), y la Sentencia de la Audiencia Nacional (en la cual se desestima que deba anularse la línea de deslinde en cuanto fija la servidumbre en 100 metros, manteniendo lo dispuesto en la O.M.), no fue solventada hasta la resolución emitida el 14 de mayo de 2013 por la Dirección General de Costas [publicada en el BOIB n88 de 22 de junio de 2013], siguiendo la decisión de la resolución estimatoria del recurso de reposición.

13) El 5 de mayo de 2006, la mercantil "Inmobiliaria Portinatx S.L." (siendo socios los actores) y la sociedad "Zear Grupo de Inversión Inmobiliaria, S.A." suscribieron una promesa bilateral de venta de las dos fincas registrales, señalando como plazo 15 meses desde su firma para suscribir el contrato de compraventa, el cual finalizaba el 5 de agosto de 2007. El 29 de junio de 2007, 
se disolvió la mercantil vendedora, iniciándose período de liquidación. El 2 de agosto de 2007 se firmó el contrato privado de compraventa, pero sin que se formalizase en escritura pública en el plazo fijado como condición resolutoria, antes del 1 de diciembre de 2007. El 21 de diciembre de 2007, tras la liquidación de la sociedad, se adjudicó la propiedad de los terrenos a los Sres. Felix.»

A la vista d'aquesta exposició el Tribunal tracta la qüestió central del plet: si es pot desprendre de tot això que existís una actuació municipal que hagués produït efectes lesius en el patrimoni dels Srs. Felix que motivin acordar l'existència d'un supòsit de responsabilitat patrimonial.

El Tribunal determina que s'ha de rebutjar la petició de responsabilitat patrimonial a partir del relat de fets consignat en el Fonament Segon de la Sentència. I ho fa sobre la base dels arguments següents:

«En primer lugar, el contrato de compraventa de las dos fincas registrales lindantes con los vértices 750 y 751 del deslinde, quedó resuelto por no elevarse el contrato privado suscrito el 2 de agosto de 2007 a escritura pública antes del 1 de diciembre de 2007, y ello por motivos que no constan a esta Sala, pero que en todo caso fueron anteriores a la aprobación de la O. M. de 31 de diciembre de 2008.

En segundo lugar, la disolución de la entidad propietaria y vendedora devino en junio de 2007, y su liquidación efectiva en fecha 21 de diciembre de 2007, siendo anteriores a la aprobación ministerial de la línea de deslinde con una extensión de la servidumbre de protección en 100 metros, en lugar de 20 metros.

En tercer lugar, porque resulta claramente constatado que el Ayuntamiento, tanto en el expediente de deslinde, como en el procedimiento de revisión del planeamiento, siempre defendió que los terrenos propiedad de los actores debían ser considerados como urbanos por consolidación de los servicios básicos, y que, consiguientemente, la servidumbre de protección debía tener una anchura de 20 metros, de acuerdo con la disposición transitoria tercera de la Ley de Costas. 
A partir de la O.M. de 31 de diciembre de 2008 y de la resolución de 27 de septiembre de 2011, estimatoria del recurso de reposición formulado por los actores contra el deslinde, no se desprende que la Administración competente en materia de demanio marítimo-terrestre fijase la servidumbre en 100 metros a causa de los informes desfavorables emitidos por el Consistorio, sino que se colige que el Ministerio señaló la citada anchura al interpretar los documentos remitidos por el Ayuntamiento, ya que la Administración estatal apreció que no tenían la consideración de suelo urbano a resultas de los datos que expresaba esta documentación, sin que en ningún caso el Ayuntamiento, directa ni implícitamente, se hubiese posicionado en contra de esta clasificación urbanística, sino todo lo contrario, siempre mantuvo un comportamiento defensor del carácter urbano de las parcelas y de establecer una extensión de 20 metros de la citada servidumbre legal.»

Tota aquesta línia argumental condueix al Tribunal d'apel·lació a desestimar el recurs i confirmar la sentència del Jutjat del Contenciós impugnada. Es considera que la situació bàsica del sòl no tenia la consideració de sòl urbà $i$ per aquest motiu, i a la vista de la documentació que es trobava en poder de la Demarcació de Costes, la servitud es va situar en 100 metres (i no en vint). Per la qual cosa no hi ha cap responsabilitat de l'ajuntament i la via que corresponia era impugnar l'Ordre Ministerial aprovada. 